\title{
T-box 3 overexpression is associated with poor prognosis of non-small cell lung cancer
}

\author{
YUEMING WU $^{1}$, JIANG FENG ${ }^{1}$, WEIWEI HU ${ }^{1}$ and YAWEI ZHANG ${ }^{2}$ \\ ${ }^{1}$ Department of Thoracic Surgery, The People's Hospital of Dongyang City, Dongyang, Zhejiang 322100; \\ ${ }^{2}$ Department of Thoracic Surgery, Fudan University Shanghai Cancer Center, Shanghai 200433, P.R. China
}

Received August 18, 2015; Accepted January 13, 2017

DOI: $10.3892 / 01.2017 .5855$

\begin{abstract}
T-box 3 (Tbx3), a member of the T-box transcription factor family, serves a crucial role in embryonic development and cancer progression. Previous studies have demonstrated the clinical significance of $T b x 3$ in numerous types of cancer. However, the expression level and pathological function of Tbx3 in non-small cell lung cancer (NSCLC) are unknown. To the best of our knowledge, the present study provided the first evidence demonstrating the clinicopathological significance of $T b x 3$ in NSCLC. $T b x 3$ was revealed to be overexpressed in NSCLC cell lines and tissues obtained from patients with NSCLC by reverse transcription-quantitative polymerase chain reaction and western blot analysis. Downregulation of $T b x 3$ by Tbx3-specific short hairpin RNA decreased cell proliferation in NSCLC cell lines, but there was a slight increase in the cell population of the $\mathrm{G}_{1}$ phase. Furthermore, depletion of Tbx3 expression significantly decreased the cell migration distance. In addition, overexpression of $T b x 3$ was notably associated with tumor size, tobacco smoking status, tumor-node-metastasis stage and differentiation. These results demonstrated the importance of $T b \times 3$ in the pathological progression of NSCLC and may serve as a potential therapeutic target for NSCLC.
\end{abstract}

\section{Introduction}

Lung cancer may be classified into two main groups, small-cell lung cancer (SCLC) and non-small cell lung cancer (NSCLC) (1). Epidemiological data revealed that tobacco smoke exposure is the leading risk factor of lung cancer and NSCLC accounts for $85 \%$ of lung cancer cases $(2,3)$. Despite encouraging progress made in the early detection and therapeutic strategies, lung cancer remains one of the most common malignancies worldwide, with a poor prognosis of NSCLC

Correspondence to: Dr Yueming Wu, Department of Thoracic Surgery, The People's Hospital of Dongyang City, 60 Wuning West Road, Dongyang, Zhejiang 322100, P.R. China

E-mail: yueming_wu@qq.com

Key words: non-small cell lung cancer, Tbx3, biomarker, proliferation, prognosis patients and a relative low 5-year survival rate (3). Therefore, novel prognostic biomarkers should be identified and applied in combination with current staging systems to improve the prognostic evaluation and clinical management of patients with NSCLC.

T-box transcription factors are highly evolutionarily conserved and serve critical roles in a variety of cellular biological events (4). T-box 3 (Tbx3), a member of the T-box transcription factor family, is widely expressed in the nervous system, heart, lungs and pancreas (4). Accumulating evidence has demonstrated that $T b x 3$ is involved in the developmental process by binding to the T-box motif with a 20-24 nucleotide palindromic sequence, the T-site, or half of the sequence in the promoters of target genes (5). A mutation of Tbx3 was demonstrated to be closely associated with the pluripotency of embryonic stem cells and the invasiveness of cancer (6). In resectable pancreatic carcinoma (7), melanoma (8), bladder cancer (9) and colorectal cancer (10), Tbx3 was revealed to be overexpressed and associated with poor prognosis of cancer. Recently, $T b x 3$ was reported to serve a key role in melanoma migration and invasion by acting as a key substrate of protein kinase $\mathrm{B}$ and thus inducing the repression of E-cadherin (8). Additionally, $T b x 3$ is involved in the anti-proliferative event mediated by the transforming growth factor $\beta 1$ signaling pathway by repressing the oncogenic $T b \times 2$ in human breast epithelial MCF-12A cells (11).

The expression of Tbx3 in lung tissue under normal physiological conditions has previously been established (12). However, to the best of our knowledge, the expression status of $T b x 3$ in patients with NSCLC has not been investigated to date. In order to understand the role of $T b x 3$ in cancer and to improve the poor prognosis of NSCLC, further investigation into the expression status and clinical significance of $T b x 3$ in NSCLC is required. The present study evaluated $T b x 3$ expression at the messenger RNA (mRNA) and protein levels in NSCLC tissue samples, and analyzed the correlations between Tbx3 expression and various clinicopathological parameters. Finally, the present study aimed to explore the association between $T b x 3$ overexpression and the prognosis of NSCLC.

\section{Materials and methods}

Patients and sample collections. A total of 86 patients with NSCLC (46 males and 40 females) were enrolled in the present 
study. All patients underwent treatment at the People's Hospital of Dongyang City (Dongyang, China) between August 2007 and October 2010. The stage of cancer of patients was classified according to the tumor-node-metastasis (TNM) staging system. The tumor tissues and matched adjacent normal tissues were frozen in liquid nitrogen following surgical resection and preserved at $-80^{\circ} \mathrm{C}$ prior to use. Clinicopathological data were collected, including age, gender, tumor size, tobacco smoking status, alcohol drinking status, TNM stage and differentiation. Patients characteristics are summarized in Table I. The present study was approved by the ethics committee of The People's Hospital of Dongyang City. Written informed consent was obtained from all patients prior to enrollment in the present study.

Cell lines and cell culture. The A549 and NCI-H460 human NSCLC cell lines were obtained from the American Type Culture Collection (ATCC; Manassas, VA, USA). For cell culture, Dulbecco's modified Eagle's medium supplemented with $10 \%$ fetal bovine serum (Gibco; Thermo Fisher Scientific, Inc., Waltham, MA, USA), $100 \mathrm{U} / \mathrm{ml}$ penicillin and $100 \mathrm{U} / \mathrm{ml}$ streptomycin were used, and a $100 \%$ humidified atmosphere was maintained $\left(37^{\circ} \mathrm{C}, 5 \% \mathrm{CO}_{2}\right)$.

Tbx3 depletion in A549 and NCI-H460 cells. The sequences of Tbx3-specific short hairpin RNA (shRNA) and control shRNA were described in a previous study (13) and obtained from Invitrogen (Thermo Fisher, Scientific, Inc.). A549 and NCI-H460 cell lines stably expressing $T b x 3$ shRNA were synthesized by retroviral transduction of the pSUPER.Retro.Puro (Addgene, Inc., Cambridge, MA, USA) vector encoding shRNA against $T b x 3$, followed by selection in $1 \mu \mathrm{g} / \mathrm{ml}$ puromycin.

Cell proliferation assay. The MTT assay was performed to evaluate the level of cell proliferation. Following transfection, cells with $T b x 3$-specific shRNA or control shRNA were seeded in 96-well plates at a density of 4,000 cells/well and incubated under the aforementioned conditions $\left(37^{\circ} \mathrm{C}, 5 \%\right.$ $\mathrm{CO}_{2}$ ). Following 12, 24, 48 and $72 \mathrm{~h}$ culture, $20 \mu \mathrm{l}$ of $5 \mathrm{mg} / \mathrm{ml}$ MTT (Sigma-Aldrich; Merck KGaA, Darmstadt, Germany) was added to each well. The plates were incubated for a further $4 \mathrm{~h}$ under the same conditions $\left(37^{\circ} \mathrm{C}, 5 \% \mathrm{CO}_{2}\right)$, and subsequently $150 \mu \mathrm{l}$ of dimethylsulfoxide was added until the purple formazan was completely dissolved. The absorbance of each well was determined using the Multiskan ${ }^{\circledR}$ Spectrum (Thermo Fisher Scientific, Inc.) at a wavelength of $490 \mathrm{~nm}$. Each independent experiment was performed three times.

Total RNA extraction and reverse transcription-quantitative polymerase chain reaction $(R T-q P C R)$ analysis. Total RNA was extracted from the transfected cells, tumor tissues and matched normal tissues using an RNeasy Mini kit (Qiagen $\mathrm{GmbH}$, Hilden, Germany), according to the manufacturer's protocol, and first-strand complementary DNA was synthesized from $5 \mathrm{ng}$ total RNA using the QuantiTect Reverse Transcription kit (Qiagen $\mathrm{GmbH}$ ).

The expression level of Tbx3 in transfected cells, tumor tissues and normal tissues was quantified using SYBR ${ }^{\circledR}$-Green PCR Master Mix (Applied Biosystems; Thermo Fisher Scientific, Inc.). RT-qPCR was performed using an ABI-7500
Table I. Correlation of Tbx3 expression level with the clinicopathological features of patients with non-small cell lung cancer.

\begin{tabular}{|c|c|c|c|c|}
\hline \multirow[b]{2}{*}{ Variable } & \multirow[b]{2}{*}{ Cases, $\mathrm{n}$} & \multicolumn{2}{|c|}{$\begin{array}{c}\text { Tbx3 } \\
\text { expression } \\
\text { level }\end{array}$} & \multirow[b]{2}{*}{ P-value } \\
\hline & & High & Low & \\
\hline \multicolumn{5}{|l|}{ Gender } \\
\hline Male & 46 & 30 & 16 & 0.116 \\
\hline Female & 40 & 31 & 9 & \\
\hline \multicolumn{5}{|l|}{ Age, years } \\
\hline$\geq 50$ & 51 & 33 & 18 & 0.146 \\
\hline$<50$ & 35 & 28 & 7 & \\
\hline \multicolumn{5}{|l|}{ Tumor size, $\mathrm{cm}$} \\
\hline$\geq 5$ & 45 & 32 & 13 & 0.035 \\
\hline$<5$ & 41 & 29 & 12 & \\
\hline \multicolumn{5}{|c|}{ Tobacco smoking status } \\
\hline Non-smoker & 38 & 28 & 10 & 0.036 \\
\hline Smoker & 48 & 33 & 15 & \\
\hline \multicolumn{5}{|c|}{ Alcohol drinking status } \\
\hline Non-drinker & 49 & 33 & 16 & 0.062 \\
\hline Drinker & 37 & 28 & 9 & \\
\hline \multicolumn{5}{|l|}{ Differentiation } \\
\hline Poor & 46 & 32 & 14 & 0.014 \\
\hline Well/moderate & 40 & 29 & 11 & \\
\hline \multicolumn{5}{|l|}{ Tumor stage } \\
\hline I-II & 42 & 30 & 12 & 0.002 \\
\hline III-IV & 44 & 31 & 13 & \\
\hline
\end{tabular}

Tbx3, T-box 3 .

Real-Time PCR system (Applied Biosystems; Thermo Fisher Scientific, Inc.) and analyzed using ABI SDS software (version 2.0.6; Applied Biosystems; Thermo Fisher Scientific, Inc.). The primers used for RT-qPCR were synthesized by Invitrogen (Thermo Fisher Scientific, Inc.) and listed as follows: Human Tbx3 sense 5'-CCCGAAGAAGACGTAGAA GATGAC-3' and antisense 5'-CCCGAAGAAGAGGTGGAG GACGAC-3'; human $\beta$-actin (ACTB) sense 5'-CCTCCATCG TCCACCGCAAATG-3' and antisense 5'-TGCTGTCACCTT CACCGTTCCA-3'. The following optimized cycling conditions were used: $95^{\circ} \mathrm{C}$ for $10 \mathrm{~min}$, followed by 40 cycles at $95^{\circ} \mathrm{C}$ for $15 \mathrm{sec}$ and $55^{\circ} \mathrm{C}$ for $15 \mathrm{sec}$. Each sample was analyzed in triplicate and the mean value was determined. The expression level of $T b x 3$ was normalized to the endogenous control, $A C T B$. The relative expression level of $T b x 3$ was evaluated using the $2^{-\triangle \Delta C q}$ method (14).

Western blot analysis. Western blotting was performed to assess the expression level of $T b x 3$ in transfected cells, tumor tissues and normal tissues. Protein concentration was determined using the standard Bradford assay kit (cat. no. P0006; Beyotime Institute of Biotechnology, Haimen, China). Equal 
amount of total protein was loaded onto a $10 \%$ SDS-PAGE gel and blotted onto a nitrocellulose membrane in a humid environment. The membrane was blocked with $5 \%$ milk in TBS containing $0.05 \%$ Tween 20 (TBST) and incubated with anti-Tbx3 antibody (dilution, 1:2,000; cat no. ab89220; Abcam, Cambridge, UK) at room temperature for $1 \mathrm{~h}$. The anti- $\beta$-actin antibody (dilution, 1:2,000; cat. no. ab6276; Abcam) was used as the internal control and incubated at room temperature for $1 \mathrm{~h}$. Subsequently, the membrane was washed three times with TBST and incubated with a secondary anti-rabbit immunoglobulin $\mathrm{G}$ antibody conjugated to horseradish peroxidase (dilution, 1:5,000; cat. no. SC-2054; Santa Cruz Biotechnology, Inc., Dallas, TX, USA) at room temperature for $1 \mathrm{~h}$. Blots were developed using the enhanced chemiluminescence method, according to the manufacturer's protocol (Pierce; Thermo Fisher Scientific, Inc.). Autoradiography signals were analyzed using an ImageQuant RT ECL gel imaging system (GE Healthcare Bio-Sciences, Pittsburgh, PA, USA). The gray-scale ratio of Tbx3 to $\beta$-actin in each sample was considered as the relative protein expression level. Patients who exhibited Tbx 3 expression levels in tumor tissues that was higher compared with adjacent noncancerous tissues were classified into the high Tbx 3 expression group. Patients with a lower Tbx 3 expression level in tumor tissues compared with the adjacent noncancerous tissues were classified into low Tbx3 expression group.

Flow cytometry for cell cycle assessment. Following transfection of Tbx3-specific shRNA or control shRNA, the A549 and NCI-H460 cells were collected by trypsinization (Sigma-Aldrich; Merck KGaA), washed with PBS and fixed with $70 \%$ cold ethanol overnight at $-20^{\circ} \mathrm{C}$. The ethanol-suspended cells were then collected, washed and stained with propidium iodide (PI) staining buffer ( $5 \mu \mathrm{g} / \mathrm{ml} \mathrm{PI}$ and $0.25 \mu \mathrm{g} / \mathrm{ml}$ RNase) for $30 \mathrm{~min}$ in the dark at room temperature. Finally, cell cycle analysis was performed by evaluating the DNA content of control shRNA and Tbx3-specific shRNA-transfected NSCLC cell lines using a FACSCalibur ${ }^{\mathrm{TM}}$ flow cytometer (BD Biosciences, Franklin Lakes, NJ, USA), according to the manufacturer's protocol. The results were analyzed using the ModFit LT software (version 3.2; Verity Software House, Inc., Topsham, ME, USA).

Cell migration assay. Cell migration in culture was determined using a two-dimensional in vitro scratch motility assay, as previously described (15). The A549 and NCI-H460 cell lines transfected with control shRNA or Tbx3-specific shRNA were seeded at $2 \times 10^{6}$ cells/well in 6 -well plates. A linear wound was made by scratching cells with the tip of a p1000 pipette (Axygen; Corning Life Sciences, Tewksbury, MA, USA). To prevent cell proliferation, mitomycin C (Sigma-Aldrich; Merck KGaA) was added at a final concentration of $10 \mu \mathrm{g} / \mathrm{ml}$. Cells were incubated at $37^{\circ} \mathrm{C}$ in $5 \% \mathrm{CO}_{2}$. The wound widths were measured at the time of the scratching $(0 \mathrm{~h})$ and at various time points $(2,4$ and $6 \mathrm{~h})$. Images were captured using a BX53 microscope (Olympus Corporation, Tokyo, Japan), and migration distances were measured using AxioVision software version 4.8 (Zeiss $\mathrm{GmbH}$, Jena, Germany). The difference in width represents the distance migrated in $\mu \mathrm{m}$.
Statistical analysis. All the data collected in the present study were analyzed using SPSS software (version 20.0; IBM SPSS, Armonk, NY, USA). Data are expressed as the mean \pm standard deviation. Differences between groups were determined by the $\chi^{2}$ test. The Kaplan-Meier log-rank test was used for survival analysis, whereas prognostic factors were examined by univariate and multivariate analyses (Cox's regression test). $\mathrm{P}<0.05$ was considered to indicate a statistically significant difference.

\section{Results}

Tbx3 is highly expressed in NSCLC tissues. In order to evaluate the expression level of Tbx3 in NCLC tissues, RT-qPCR and western blot analysis were performed to quantify the $T b x 3$ expression levels. As presented in Fig. 1A and B, the mRNA expression level of $T b x 3$ in normal or tumor tissues was determined. The present study demonstrated that $61 / 86$ patients with NSCLC (70.9\%) displayed a significantly higher Tbx3 gene expression level in tumor tissues compared with that in adjacent normal tissues (overexpressed group); thus, in the majority of cases, Tbx3 was overexpressed in patients with NSCLC. The remaining 25 cases displayed lower $T b x 3$ gene expression level in tumor tissues compared with those in normal tissues (underexpressed group). Furthermore, the results of the western blot analysis verified the conclusions drawn from RT-qPCR. The protein level of $T b x 3$ in the overexpressed group was significantly higher in tumor tissues compared with that in normal tissues $(\mathrm{P}<0.001$, Fig. $1 \mathrm{C}$ and $\mathrm{E})$. Additionally, the expression level of $T b x 3$ was lower in tumor tissues compared with that in the normal tissues of the underexpressed group $(\mathrm{P}<0.05$; Fig. 1D and F).

Tbx3 overexpression promotes cell proliferation. To evaluate the role of $T b x 3$ in the process of tumorigenesis, $T b x 3$-specific shRNA was introduced to the A549 and NCI-H460 NSCLC cell lines with the aim of downregulating the expression level of $T b x 3$. The gene expression level of $T b x 3$ in transfected cells was determined by RT-qPCR. As demonstrated in Fig. 2A, the mRNA expression level of Tbx3 in A549 and NCI-H460 cells transfected with $T b x 3$-specific shRNA was significantly decreased $(\mathrm{P}<0.05)$ compared with that in the control shRNA-transfected cells. Western blot analysis confirmed that the level of $T b x 3$ was significantly downregulated with the transfection of Tbx3-specific shRNA ( $\mathrm{P}<0.05$; Fig. 2B). These results indicated that the knockdown of Tbx3 significantly decreased the mRNA and protein expression levels of $T b x 3$, which suggested the highly regulated control of Tbx3-specific shRNA $(\mathrm{P}<0.05)$.

Furthermore, the role of $T b x 3$ in cell proliferation was assessed by MTT assay. The results demonstrated that the optical densities of A549 or NCI-H460 cells transfected with Tbx3-specific shRNA were significantly lower compared with those of the A549 or NCI-H460 cells with the control shRNA $(\mathrm{P}<0.05$; Fig. 2C), which indicated that $T b x 3$ overexpression may promote cell proliferation.

Downregulation of Tbx3 affects the distribution of cell cycle proportion. It has been well established that Tbx3 participates in the regulation of the cell cycle (16). In order to 
$\mathbf{A}$

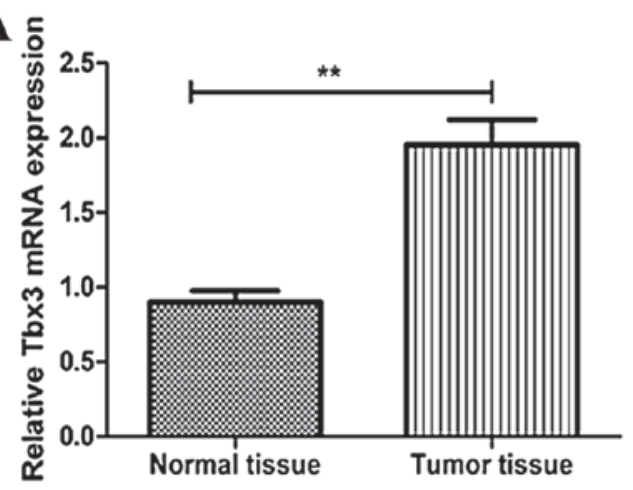

C Overexpressed group
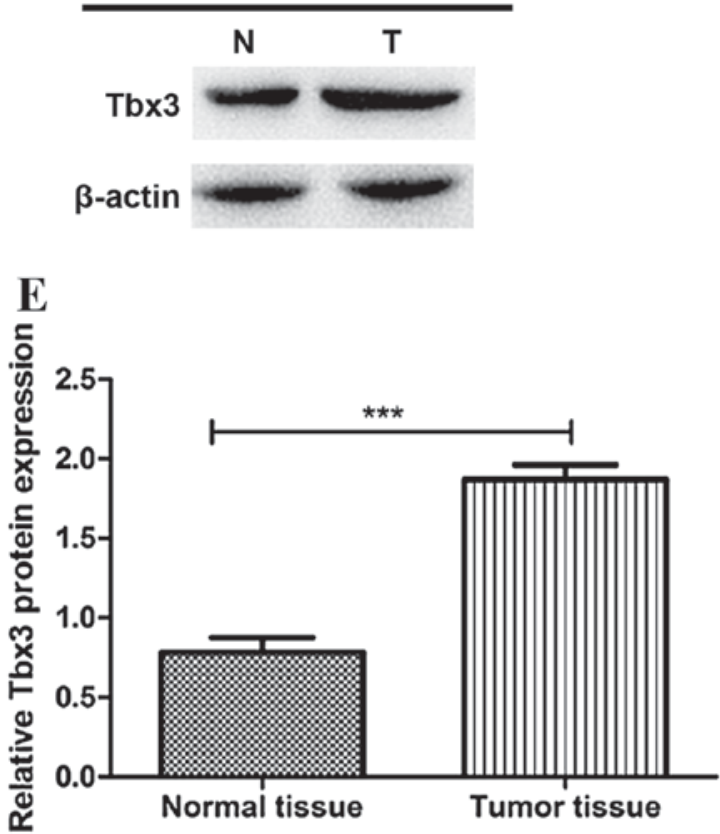

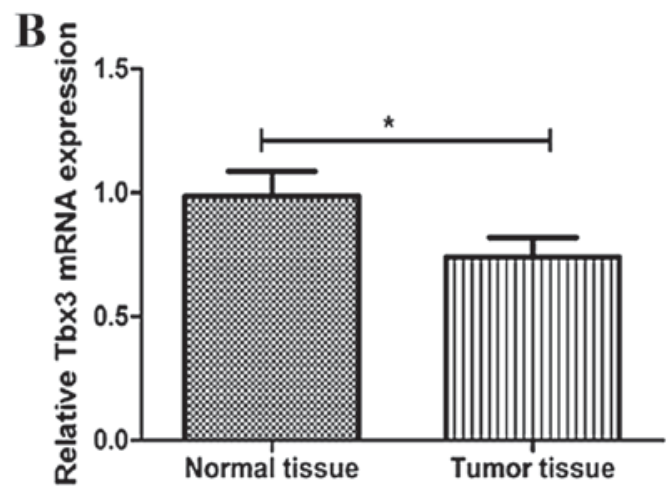

D

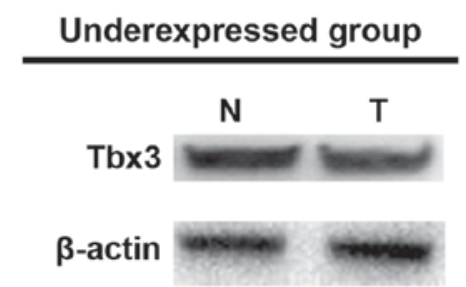

$\mathbf{F}$

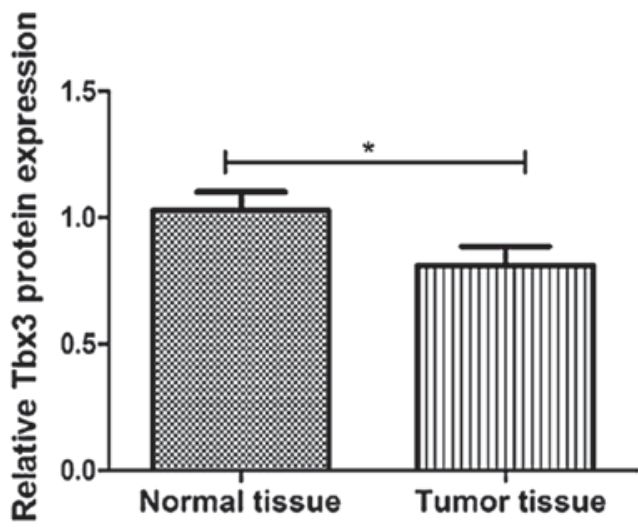

Figure 1. Analysis of Tbx3 expression levels in tumor tissues and adjacent normal tissues. (A and B) Tbx3 expression in the (A) overexpressed and (B) underexpressed groups. (C and D) Western blot analysis of the protein level of Tbx3 in tumor and normal tissues in the (C) overexpressed and (D) underexpressed groups. (E and F) Gray-color analysis of Tbx3 expression in the (E) overexpressed and (F) underexpressed groups. ${ }^{* * *} \mathrm{P}<0.001,{ }^{* *} \mathrm{P}<0.01,{ }^{*} \mathrm{P}<0.05$. Tbx3, T-box 3; N; normal; T, tumor; mRNA, messenger RNA.

investigate the role of $T b x 3$ in regulating the cell cycle, flow cytometry was performed to determine whether $T b x 3$ overexpression affects the cell cycle of A549 and NCI-H460 cells. The results (Fig. 2D and E) indicated that the Tbx3-specific shRNA-transfected cells displayed a slight increase in cell population in the $\mathrm{G}_{1}$ growth phase, whereas the proliferation of cells in the $S$ and $G_{2} / M$ phases were decreased compared with those of the control cells. The aforementioned results suggested that the expression level of Tbx3 may affect the cell cycle distribution and lead to the change in cell proliferation.

Tbx3 overexpression promotes cell migration. Investigating the clinicopathological function of $T b x 3$ is crucial for understanding tumorigenesis. The effect of $T b x 3$ overexpression on cell migration required further study. Therefore, the present study analyzed the mobility of cells transfected with Tbx3-specific shRNA or control shRNA by performing a two-dimensional scratch assay. As presented in Fig. 2F, the migration distance of cells transfected with $T b \times 3$-specific
shRNA was significantly lower $(\mathrm{P}<0.05)$ than that of the control shRNA-transfected group at all the selected time points (2, 4 and $6 \mathrm{~h}$ ). The results presented (Fig. 2F) confirmed that $T b x 3$ overexpression promoted cell migration in A549 and NCI-H460 cells.

Clinical significance of Tbx3 overexpression in NSCLC. The clinical significance of Tbx3 overexpression in colorectal cancer (10) and pancreatic carcinoma (7) has been revealed in previous studies. Therefore, the clinical significance of $T b \times 3$ expression in NSCLC patients was analyzed in the present study by evaluating the correlation of $T b x 3$ expression with clinicopathological characteristics. It was demonstrated that Tbx3 expression was significantly associated with tumor size $(\mathrm{P}=0.035)$, tobacco smoking status $(\mathrm{P}=0.036)$, TNM stage $(\mathrm{P}=0.002)$ and differentiation $(\mathrm{P}=0.014)$ (Table I). In addition, the 5-year overall survival rates were 13.14 and $49.56 \%$ in the overexpressed and underexpressed groups, respectively. Notably, the survival rates of these two groups were 
A

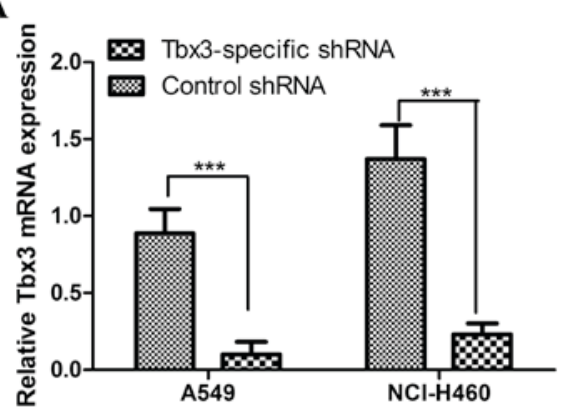

B

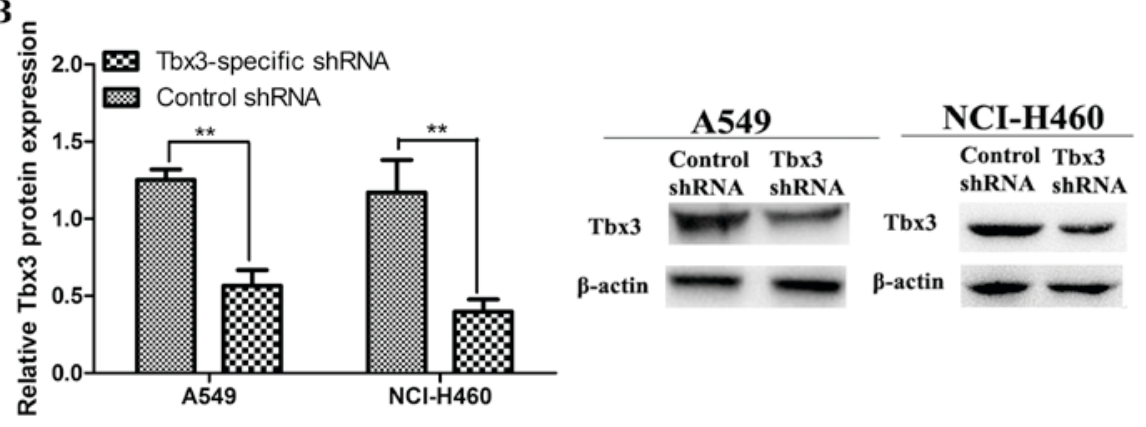

c

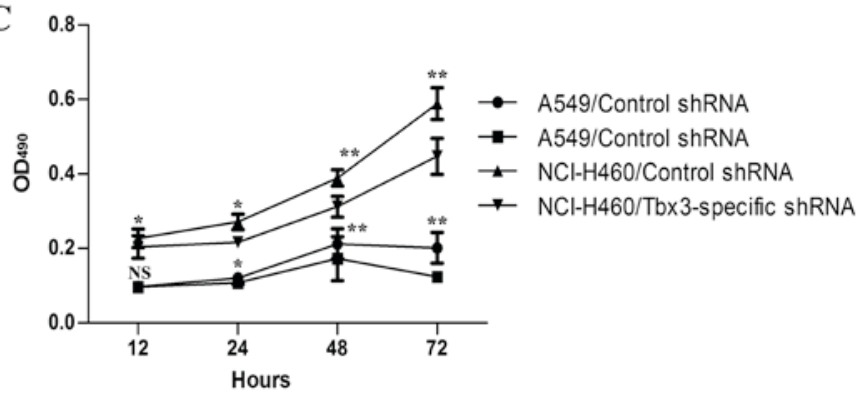

E

A549
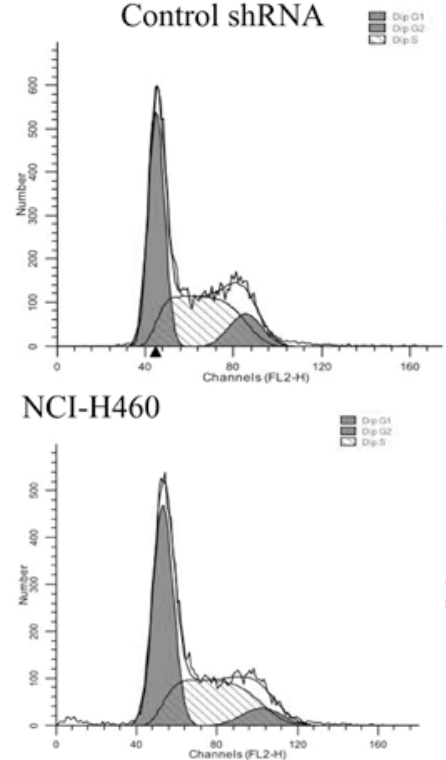

Tbx3-specific shRNA

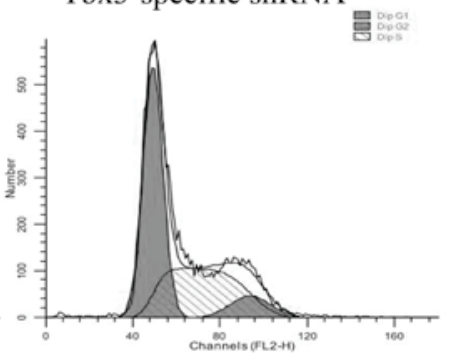

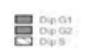

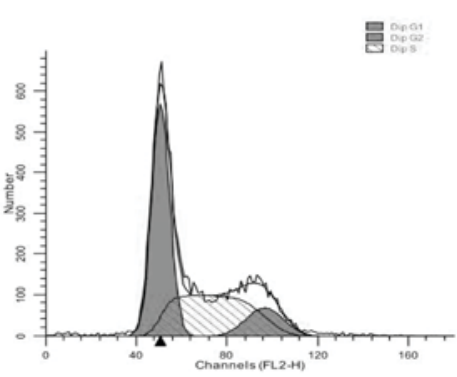

D

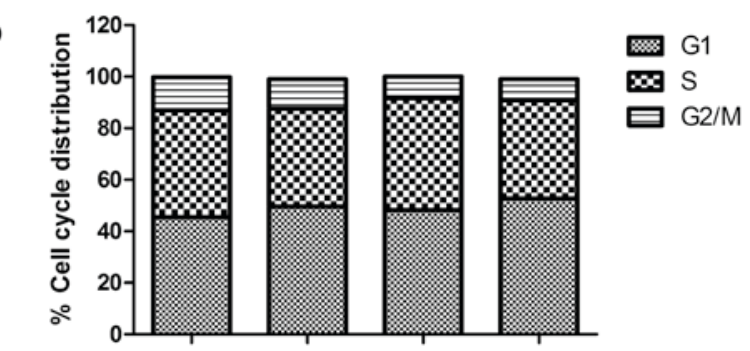

Figure 2. Tbx3 downregulation in A549 and NCI-H460 non-small cell lung cancer cell lines. (A) Reverse transcription-quantitative polymerase chain reaction analysis of the Tbx3 expression level of transfected cells with the control shRNA or Tbx3-specific shRNA. (B) Western blot analysis of the protein level of $\beta$-actin and Tbx3 in transfected cells with control shRNA and Tbx3-specific shRNA. (C) MTT assay of the transfected cell proliferation rate. (D) Cell cycle distribution of control shRNA- and Tbx3-specific shRNA-transfected cells; (E) Flow cytometry analysis of the cell cycle distribution of control shRNA- or Tbx3-specific shRNA-transfected cells. (F) Cell migration distance of control shRNA- and Tbx3-specific shRNA-transfected cells at specific time-points (2, 4 and 6 h). ${ }^{* * *} \mathrm{P}<0.001,{ }^{* *} \mathrm{P}<0.01,{ }^{*} \mathrm{P}<0.05$. Tbx3, T-box 3; shRNA, short hairpin RNA; OD, optical density.

significantly different $(\mathrm{P}=0.046)$; thus, the patients with high Tbx3 expression levels had decreased 5-year survival rates compared with those with low Tbx3 expression (Fig. 3).

Tbx3 overexpression is associated with the poor prognosis of NSCLC. The association between Tbx3 expression and prognosis in patients with NSCLC was evaluated by univariate and multivariate analyses. Multivariate analysis using Cox's proportional hazards model was performed to analyze whether one factor can be considered as an independent factor for the prognosis of NSCLC patients, focusing on the factors that significantly affect the survival rate of patients with NSCLC obtained from univariate analysis. From the univariate and multivariate analysis results, the same conclusions could be drawn: Tumor differentiation, tumor size, tobacco smoking status, tumor stage and Tbx3 expression level were identified as independent prognosis factors for patients with NSCLC (Table II). 
Table II. Univariate and multivariate analyses of overall survival rate.

\begin{tabular}{|c|c|c|c|c|c|c|}
\hline \multirow[b]{2}{*}{ Variables } & \multicolumn{2}{|c|}{ Univariate analysis } & \multirow[b]{2}{*}{ P-value } & \multicolumn{2}{|c|}{ Multivariate analysis } & \multirow[b]{2}{*}{ P-value } \\
\hline & HR & $95 \% \mathrm{CI}$ & & HR & $95 \% \mathrm{CI}$ & \\
\hline Tbx3 & 2.131 & $1.022-4.445$ & 0.018 & 2.252 & $1.052-4.817$ & 0.026 \\
\hline Age & 0.908 & $0.418-1.971$ & 0.507 & 0.913 & $0.421-1.980$ & 0.514 \\
\hline Gender & 1.003 & $0.456-2.208$ & 0.391 & 0.997 & $0.453-2.197$ & 0.373 \\
\hline Tumor size & 2.242 & $1.039-4.840$ & 0.030 & 1.917 & $0.931-3.950$ & 0.034 \\
\hline Tobacco smoking status & 2.260 & $1.057-4.834$ & 0.029 & 2.229 & $1.026-4.844$ & 0.031 \\
\hline Alcohol drinking status & 1.510 & $0.741-3.076$ & 0.164 & 1.588 & $0.761-3.314$ & 0.108 \\
\hline Differentiation & 2.311 & $1.094-4.881$ & 0.026 & 2.015 & $1.066-4.859$ & 0.028 \\
\hline Tumor stage & 2.553 & $1.177-5.538$ & 0.014 & 2.367 & $1.135-4.938$ & 0.016 \\
\hline
\end{tabular}

HR, hazard ratio; CI, confidence interval; Tbx3, T-box 3 .

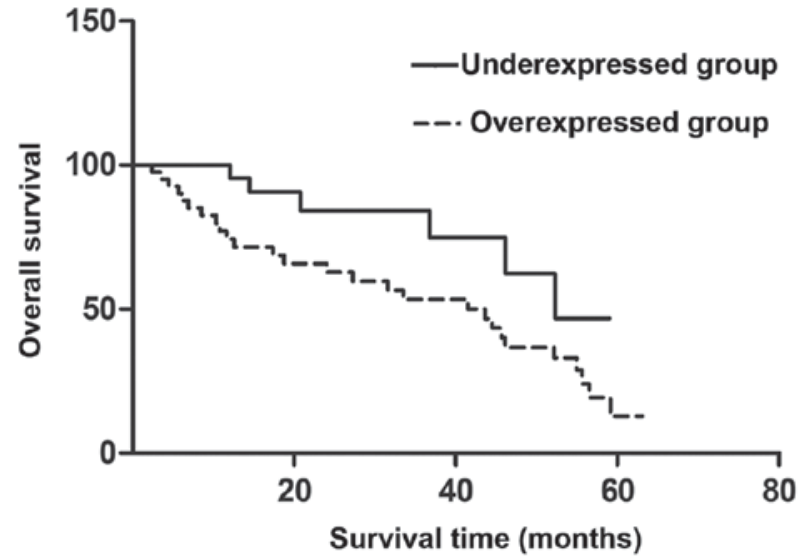

Figure 3. Overall survival rate evaluated by Kaplan-Meier curves and classification of 86 patients into the $T b x 3$ overexpressed $(n=61)$ or $T b x 3$ underexpressed groups $(\mathrm{n}=25)$. Non-small cell lung cancer patients with Tbx3 overexpressed have a lower 5-year survival rate compared with that exhibited by patients in the underexpressed group.

\section{Discussion}

Each year, 1.2 million novel NSCLC cases are diagnosed worldwide (2). Despite progress being made in the development of therapeutic strategies for NSCLC (17-19), the 5-year overall survival rate remains low (10-15\%) (3). One reason for this is the high frequency of tumor metastasis in patients with NSCLC (20). Metastasis is widely accepted as one of the most decisive factors influencing the prognosis of patients with cancer (21). Therefore, it is imperative to identify effective predictive factors for the diagnosis and treatment of NSCLC. As a member of the Tbx2 subfamily, Tbx3 has been confirmed to be implicated in a number of human diseases, particularly cancer $(6-8,10)$. The overexpression of $T b x 3$ is present in several cancer subtypes, including colorectal cancer and pancreatic carcinoma $(7,10)$. More importantly, the poor prognosis of cancer is also associated with the overexpression of Tbx3 $(7,10)$. Previous studies have established that $T b x 3$ serves an important role in the regulation of cell proliferation, cell cycle, cell apoptosis and cell migration in tumor cells $(7,8,10)$.
The expression of $T b x 3$ in lung tissues has previously been demonstrated (12); however, the role of $T b x 3$ in the pathogenesis of NSCLC requires further investigation. To the best of our knowledge, the present study evaluated the expression level of Tbx3 in NSCLC and its association with the clinicopathological characteristics of patients with NSCLC for the first time. $T b x 3$ was revealed to be overexpressed in NSCLC tissues compared with that in adjacent normal tissues by RT-qPCR and western blot analysis. Furthermore, the overexpression of $T b x 3$ is closely associated with TNM stage, differentiation and recurrence of cancer in patients with NSCLC. As a result, the present study demonstrated that patients with Tbx3 overexpression had a shorter 5-year survival rate compared with that of patients with underexpression of Tbx3. Additionally, the present study identified that $T b x 3$ overexpression was an independent prognostic biomarker for the prediction of prognosis for patients with NSCLC. Based on these findings, the present study further investigated the mechanisms underlying $T b x 3$ in tumorigenesis. Firstly, the shRNA transfection strategy was used to downregulate the expression level of Tbx3. RT-qPCR was performed to estimate the relative transcriptional level of $T b x 3$, and this indicated that the mRNA level of $T b x 3$ was significantly decreased following the $T b x 3$-specific shRNA transfection. Furthermore, the effect of $T b x 3$ expression on cell proliferation was analyzed by comparing the $T b \times 3$-specific shRNA-transfected and control shRNA-transfected cells. The results demonstrated that $T b x 3$ overexpression promoted cell proliferation. In order to determine whether cell proliferation is affected by cell cycle progression, flow cytometry was performed to analyze the cell population in various phases of the cell cycle. It was demonstrated that the $G_{1}$ phase was upregulated, whereas the $S$ and $G_{2} / M$ phases were downregulated in the $T b \times 3$-specific shRNA-transfected group compared with the findings in the control shRNA-transfected group. These results indicated that $T b x 3$ overexpression may promote cell proliferation. Furthermore, the cell migration distance of $T b x 3$-specific shRNA-transfected cells and control shRNA-transfected cells was evaluated, and the results suggested that $T b x 3$ overexpression may promote cell migration. This indicated that $T b \times 3$ overexpression serves an important role in tumorigenesis via cell proliferation and cell migration promotion. 
In conclusion, the present study demonstrated for the first time that $T b x 3$ is associated with the progression of NSCLC and may act as an independent prognostic biomarker for patients with NSCLC. Furthermore, the preliminary mechanism of Tbx3 in tumorigenesis was also discussed. Taken together, the results of the present study and previous findings $(7,8,10)$ associated with the role $T b x 3$ in cancer suggested that $T b x 3$ may potentially be an effective therapeutic target and prognostic predictor for patients with NSCLC.

\section{References}

1. Li YX, Chen YJ, Chang LJ, Hendryx M and Luo JH: Clinical biomarkers and prognosis in Taiwanese patients with Non-small cell lung cancer (NSCLC). J Cancer Ther 3: 412-423, 2012.

2. Hecht SS: Tobacco smoke carcinogens and lung cancer. J Natl Cancer Inst 91: 1194-1210, 1999.

3. Siegel R, Naishadham D and Jemal A: Cancer statistics, 2012 CA Cancer J Clin 62: 10-29, 2012.

4. Zhao ZQ, Tian W, Wang L, Wang H, Qin X, Xing Q, Pang S and Yan B: Genetic and functional analysis of the TBX3 gene promoter in indirect inguinal hernia. Gene 554: 101-104, 2015.

5. Takashima Y and Suzuki A: Regulation of organogenesis and stem cell properties by T-box transcription factors. Cell Mol Life Sci 70: 3929-3945, 2013.

6. Chan YS, Göke J, Ng JH, Lu X, Gonzales KA, Tan CP, Tng WQ, Hong ZZ, Lim YS and $\mathrm{Ng} \mathrm{HH}$ : Induction of a human pluripotent state with distinct regulatory circuitry that resembles preimplantation epiblast. Cell Stem Cell 13: 663-675, 2013.

7. Wang HC, Meng QC, Shan ZZ, Yuan Z and Huang XY: Overexpression of Tbx3 predicts poor prognosis of patients with resectable pancreatic carcinoma. Asian Pac J Cancer Prev 16: 1397-1401, 2015.

8. Peres J, Mowla S and Prince S: The T-box transcription factor, Tbx3, is a key substrate of AKT3 in melanomagenesis. Oncotarget 6: 1821-1833, 2014.

9. Du HF, Ou LP, Yang X, Song XD, Fan YR, Tan B, Luo CL and Wu XH: A new PKC $\alpha / \beta / T B X 3 / E-c a d h e r i n$ pathway is involved in PLC $\varepsilon$-regulated invasion and migration in human bladder cancer cells. Cell Signal 26: 580-593: 2014.
10. Shan ZZ, Yan XB, Yan LL, Tian Y, Meng QC, Qiu WW, Zhang $\mathrm{Z}$ and Jin ZM: Overexpression of Tbx3 is correlated with epithelial-mesenchymal transition phenotype and predicts poor prognosis of colorectal cancer. Am J Cancer Res 5: 344-353, 2015.

11. Li J, Ballim D, Rodriguez M, Cui R, Goding CR, Teng H and Prince S: The anti-proliferative function of the TGF- $\beta 1$ signaling pathway involves the repression of the oncogenic Tbx 2 by its homologue Tbx3. J Biol Chem 289: 35633-35643, 2014.

12. Washkowitz AJ, Gavrilov S, Begum S and Papaioannou VE: Diverse functional networks of Tbx3 in development and disease. Wiley Interdiscip Rev Syst Biol Med 4: 273-283, 2012.

13. Rattenbacher B, Beisang D, Wiesner DL, Jeschke JC, von Hohenberg M, St Louis-Vlasova IA and Bohjanen PR: Analysis of CUGBP1 targets identifies GU-repeat sequences that mediate rapid mRNA decay. Mol Cell Biol 30: 3970-3980, 2010.

14. Livak KJ and Schmittgen TD: Analysis of relative gene expression data using real-time quantitative PCR and the 2(-Delta Delta C(T)) method. Methods 25: 402-408, 2001

15. Peres J, Davis E, Mowla S, Bennett DC, Li JA, Wansleben S and Prince S: The highly homologous T-box transcription factors, $\mathrm{Tbx} 2$ and $\mathrm{Tbx} 3$, have distinct roles in the oncogenic process. Genes Cancer 1: 272-282, 2010.

16. Wensing LA and Campos AH: TBX3, a downstream target of TGF- $\beta 1$, inhibits mesangial cell apoptosis. Exp Cell Res 328: 340-350, 2014

17. Gao C, Yu Z, Liu S, Xin H and Li X: Overexpression of CUGBP1 is associated with the progression of non-small cell lung cancer. Tumor Biol 36: 4583-4589, 2015.

18. Liu Y, Gao WM, Siegfried JM, Weissfeld JL, Luketich JD and Keohavong P: Promoter methylation of RASSFIA and DAPK and mutations of K-ras, p53, and EGFR in lung tumors from smokers and never-smokers. BMC cancer 7: 74, 2007.

19. Zhao S, Qiu ZX, Zhang L and Li W: Prognostic values of ERK1/2 and p-ERK1/2 expressions for poor survival in non-small cell lung cancer. Tumor Biol 36: 4143-4150, 2015.

20. Ohgami A, Mitsudomi T, Sugio K, Tsuda T, Oyama T, Nishida K, Osaki T and Yasumoto K: Micrometastatic tumor cells in the bone marrow of patients with non-small cell lung cancer. Ann Thorac Surg 64: 363-367, 1997.

21. Pavese J, Odgen IM and Bergan RC: An orthotopic murine model of human prostate cancer metastasis. J Vis Exp e50873, 2013. 